\section{Application of chlorhexidine to the umbilical cord after birth in low- income settings: two randomised controlled trials}

\section{Study design}

Design: Community-based cluster-randomised trial. Allocation: Clusters were computer randomised. There were 133 clusters, with a mean population of 4100 people. Blinding: Interventions were not masked.

\section{Study question}

Setting: Rural area of Bangladesh.

Patients: All liveborn babies were eligible for enrolment. Of 35908 eligible infants, 29760 were enrolled. Over 85\% received the intervention within $24 \mathrm{~h}$ of birth. Baseline characteristics were similar between the three groups.

Intervention: Clusters were randomised to three groups: topical $4 \%$ chlorhexidine once at birth, chlorhexidine at birth plus daily cord cleansing with chlorhexidine for 7 days, or dry cord care. Village health workers visited patients daily and applied the chlorhexidine, or provided cord care guidance.

Outcomes: Primary outcome was death within 28 days after birth. Cord redness and pus, as assessed by an unblinded health worker, were also analysed.

Follow-up period: Outcomes were assessed at days 3, 6, 9, 15 and 28-35.

Patient follow-up: An intention-to-treat analysis was performed. Final health status was available for $95 \%$ of patients enrolled.

Main results Newborns in the multiple chlorhexidine group had a lower risk of severe cord redness and pus. Newborns in the single chlorhexidine group had a lower mortality rate, especially the subgroup of preterm infants. No statistically significant differences were found in mortality in the multiple chlorhexidine group. There were no adverse effects (table 1).

Conclusion Single application of chlorhexidine reduced mortality in newborns.

\section{Abstracted from}

El Arifeen S, Mullany LC, Shah R. The effect of cord cleansing with chlorhexidine on neonatal mortality in rural Bangladesh: a communitybased, cluster-randomised trial.. Lancet 2012;379:1022-8.

\section{Source(s) of funding}

USA Agency for International Development.

Table 1 Cord infection and mortality risks

\begin{tabular}{lccc}
\hline & $\begin{array}{l}\text { Severe redness } \\
\text { with pus* }\end{array}$ & Mortality* & $\begin{array}{l}\text { Mortality } \\
\text { riskt }\end{array}$ \\
\hline $\begin{array}{l}\text { Multiple } \\
\text { chlorhexidine }\end{array}$ & $0.35(0.15$ to 0.81$)$ & $0.94(0.78$ to 1.14$)$ & 26.6 \\
$\begin{array}{l}\text { Single } \\
\text { chlorhexidine }\end{array}$ & $0.77(0.40$ to 1.48$)$ & $0.80(0.65$ to 0.98$)$ & 22.6 \\
Dry cord care & 1 & 1 & 28.3 \\
\hline
\end{tabular}

*Relative risk (95\% Cl); +Risk per 1000 livebirths.

\section{Study design}

Design: Community-based cluster-randomised trial.

Allocation: Clusters were computer randomised by a statistician not involved in recruitment of patients. There were 187 clusters, with a mean population of 1000 people.

Blinding: Implementation and data collection teams were masked to allocation.

\section{Study question}

Setting: Rural area of Pakistan.

Patients: All liveborn babies were eligible for enrolment. Newborns with obvious congenital defects or cord anomalies were excluded. Of 11886 eligible infants, 9741 were enrolled. Almost $90 \%$ of families applied traditional remedies on the cord. Baseline characteristics were similar between the four groups.

Intervention: Clusters were randomised to four groups: topical $4 \%$ chlorhexidine daily for 14 days plus hand washing with antiseptic soap and water, hand washing and dry cord care, chlorhexidine without hand-washing recommendations, and dry cord care without hand-washing recommendations (control group).

Outcomes: Primary outcomes were neonatal omphalitis and mortality.

Follow-up period: Outcomes were assessed at days 1, 3, 5, 7, 14 and 28.

Patient follow-up: An intention-to-treat analysis was performed. Final health status was available for over $95 \%$ of patients enrolled.

Main results Risk of omphalitis was lower in all treatment groups. There was a trend of a lower risk of mortality in the chlorhexidine groups, but no statistically significant difference was found. There were no serious adverse effects (table 2).

Conclusion Topical chlorhexidine and hand washing reduced risk of omphalitis.

\section{Abstracted from}

Soofi S, Cousens S, Imdad A, et al. Topical application of chlorhexidine to neonatal umbilical cords for prevention of omphalitis and neonatal mortality in a rural district of Pakistan: a community-based, cluster-randomised trial. Lancet 2012;379:1029-36.

\section{Source(s) of funding}

PAIMAN (Pakistan Initiative for Mothers and Newborns) and John Snow Inc.

Table 2 Cord infection and mortality risks

\begin{tabular}{lcll}
\hline & Omphalitis* & Mortality* & $\begin{array}{l}\text { Mortality } \\
\text { riskt }\end{array}$ \\
\hline $\begin{array}{l}\text { Chlorhexidine } \\
\text { +hand washing }\end{array}$ & $0.53(0.32$ to 0.88$)$ & $0.64(0.39$ to 1.06$)$ & 20.3 \\
Hand washing & $0.67(0.48$ to 0.93$)$ & $1.23(0.82$ to 1.83$)$ & 38.4 \\
+dry cord care & & & \\
Chlorhexidine & $0.44(0.29$ to 0.67$)$ & $0.74(0.50$ to 1.08$)$ & 24.9 \\
Dry cord care & 1 & 1 & 33.8 \\
\hline
\end{tabular}

*Relative risk (95\% Cl); +Risk per 1000 livebirths. 
A

ound $99 \%$ of neonatal deaths occur in low-income and middle-income countries, where home births remain common. Cord care may prevent infection in an undefined proportion of the $30 \%$ of sepsis-related deaths. Beyond scrupulous hygiene, however, we do not know what the optimal approach to cord care is. A cluster-randomised controlled trial $(C R C T)$ in Nepal compared umbilical chlorhexidine application with education on dry cord care (the current WHO recommendation), and found a nonsignificant impact on newborn mortality. ${ }^{1}$

Two recent trials in Bangladesh and Pakistan add to the evidence. A CRCT in 133 clusters in Sylhet, Bangladesh, compared education on dry cord care with two regimens: application of $4 \%$ chlorhexidine solution soon after birth, and daily application for a week. The risk of neonatal death was lower in the single application arm, but not in the multiple application arm. A CRCT in 187 clusters in Sindh, Pakistan, provided clean home delivery kits to traditional birth attendants. In one pair of allocation arms, the kits included $4 \%$ chlorhexidine solution, to be applied by the birth attendant at delivery, and thereafter by the family for the next 2 weeks. In the other pair (the design was factorial), the kits included soap, and families were given advice on hand washing. Signs of local infection were fewer and neonatal mortality was lower in the chlorhexidine groups.

Three CRCTs have now shown some effect of chlorhexidine application on mortality. The primary implications are for low-income countries, but nosocomial infection is a significant concern for institutional births, and infection control and perinatal hygiene are critical.

\section{David Osrin}

Correspondence to Dr David Osrin, Centre for International Health and Development, UCL Institute of Child Health, London, UK; d.osrin@ucl.ac.uk

\section{Competing interests None.}

Provenance and peer review Commissioned; internally peer reviewed.

Published Online First 18 August 2012

\section{Reference}

1. Mullany L, Darmstadt G, Khatry S, et al. Topical applications of chlorhexidine to the umbilical cord for prevention of omphalitis and neonatal mortality in southern Nepal: a community-based, cluster-randomised trial. Lancet 2006;367:910-8. 